\title{
SHAPE MEMORY ALLOY ACTUATORS ARE USED TO CREATE A VARIABLE AREA JET NOZZLE FOR NOISE REDUCTION: A REVIEW
}

\author{
Shubham Chavan \\ B.Tech, Department of Aerospace engineering \\ Sandip University Nashik India \\ Pratap Gujar \\ B.Tech, Department of Aerospace engineering \\ Sandip University Nashik India
}

\begin{abstract}
The real study details the design and implementation of Shape memory alloy actuators to produce a noise-reducing variable area jet nozzle. A subscale design specification of a changeable area jet nozzle was created using SMA actuators in an asymmetrical design. Commercial transportation planes must be quieter, cleaner, and more efficient, according to the international community. The aviation industry is reacting by developing new technology in order to achieve those objectives. Changing the area of a commercial jet engine's fan nozzle can result in substantial noise reduction and reduced fuel economy. At takeoff and approach, a bigger diameter reduces jet velocity, which reduces noise. In cruise, adjusting the diameter to account for variable Mach numbers, altitude, and other factors helps optimise fan loading and minimise fuel consumption and emissions. Boeing has tested a 20 percent area change scaled variable area jet nozzle. At the nozzle exit, Shape Memory Alloy actuators were utilised to place 12 interlocking panels. To maintain a range of consistent diameters with variable flow circumstances and to alter the diameter under constant flow conditions, a closed loop control system was utilised. At each condition, acoustic data was gathered using side line microphones, and flow field measurements were taken using PIV at various crosssections. The design of a variable area nozzle is explained in this work. The diameter of the nozzle and its influence on acoustic performance are discussed. The effects of the joints between the interlocking panels are seen in the flow field data.
\end{abstract}

Keywords - Shape Memory Alloy, Jet nozzle, Actuator, Variable area jet nozzle, Variable area fan nozzle, Variable geometry chevron.

\section{INTRODUCTION}

Engineers from the Boeing Company have been studying the use of Shape Memory Alloys (SMAs) as actuators with the goal of developing novel actuation technologies utilising active materials, including the design of systems that provide considerable noise reduction in commercial aircrafts ${ }^{[15]}$. The SMA is fastened to a serrated aerodynamic structure on the nozzle of a jet engine and acts as a bending actuator. The goal of such a design is to cause actuation in the SMA components, causing the variable geometry chevrons to deflect inward (VGC). As a result of the deflection, the hot gases and cold air from the jet engine's back end combine with less turbulence, lowering the noise created during take-off and landing . ${ }^{[3,5]}$ The capacity to adjust the area of the fan nozzle will enable the next generation of commercial jet engines to be quieter, more efficient, and cleaner. Fixed fan nozzles on current commercial turbojet engines are a compromise between efficient cruise operation and suitability for takeoff and landing.In general, a smaller diameter nozzle would be more efficient for cruise operation; however, the best cruise design point is frequently unsuitable for take-off because it causes the engine to stall. VAFNs (variable area fan nozzles) eliminate existing design constraints by allowing for optimum nozzle shape throughout the flight cycle. Variating the fan nozzle size, and therefore the engine bypass ratio, is an exceptionally efficient way of lowering community noise during takeoff and approach, in addition to increased efficiency ${ }^{[8]}$.

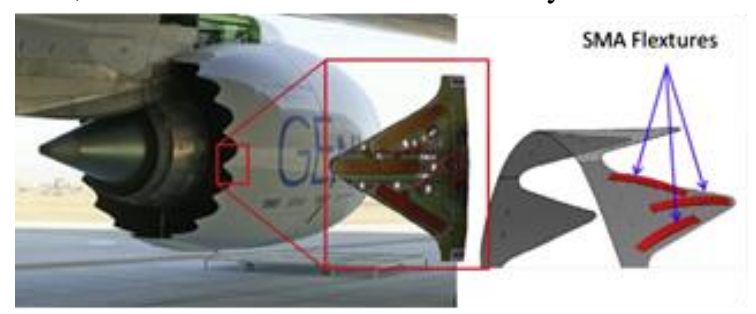

Figure 1 [A] Chevrons with Variable Geometry Chevrons have flight test hardware[21] 


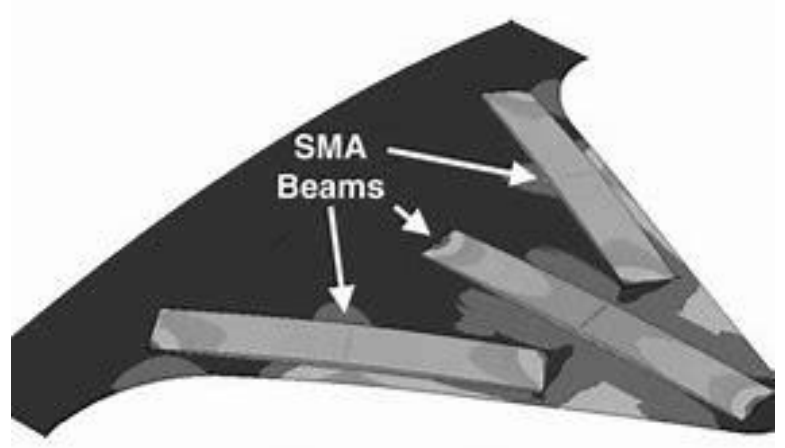

Figure 1 [B] Chevrons with Variable Geometry Chevrons have flight test hardware[22]

Boeing is now showcasing VAFN technology for future aircraft that is both realistic and feasible. Concepts for such devices that use shape memory alloy (SMA) actuators have been created. Shape Memory Alloys use a thermally induced microstructural change in the material to transfer thermal energy to mechanical energy ${ }^{[1-2]}$. At high temperatures, the Austenitic phase of the material is stable, but at low temperatures, the Martensitic phase is at equilibrium. A macroscopic actuator shape shift is caused by a thermally induced change in the SMA microstructure. SMAs are a type of alloy material that has the capacity to return to a specified form after being heated. The shape memory effect is the name for this phenomena. When a SMA is below its transition temperature, it is weak and readily plastically deformed when loaded into a new shape, where it will stay until heated ${ }^{[12]}$. Temperature and stress cause shape memory alloys to go through a phase transition. The well-known shape memory phenomenon, which is the focus of this research, is caused by thermally induced phase transition. When heated in an unconstrained state, shape memory alloys may recover a significant strain through this mechanism, and when this recovery is limited, enormous forces are generated ${ }^{[13]}$.

Following several years of successful design and testing of SMA actuators to change the geometry and form of fan nozzles and other aerodynamic systems, Boeing has developed the VAFN ideas. ${ }^{[3-5]}$ Boeing tested Variable Geometry Chevrons on a 777-300ER in full-scale flight and static engine testing in 2005 and 2006. SMA Actuators' technical preparedness for regulating the form of complicated aerostructures was shown in these tests. Figure 1 depicts the flight test hardware. Each chevron included three SMA actuators that were controlled by a simple PID controller to change the nozzle shape and correlate it with fan exhaust noise. [6] VAFNs have been proven to be beneficial on commercial jet engines in several tests and analyses. ${ }^{\text {[7] }}$ The fan nozzle of a jet engine regulates back pressure and guarantees that exhaust gas potential energy is efficiently converted to kinetic energy during expansion to ambient pressures. The fan velocity and accompanying jet noise are also reduced by expanding up the nozzle's departure region. A VAFN also allows you to choose the best region for the engine operating point for a certain flying situation, lowering the thrust specific fuel consumption (TSFC) for that segment of the flight. On commercial fan nozzle engines, significant improvements may be realised with area modifications on the scale of 10- 20\%, as shown in Figure 2. Many of the hydraulic-driven mechanical systems and wire SMA-based solutions mentioned in the literature utilise a different approach than the method presented here. While wire actuators were employed in the bulk of SMA-based concepts and designs for morphing structures in the past, the simplicity of Boeing's VAFN's monolithic flexure actuator is a huge benefit. It eliminates the problems associated with wire-based designs, which frequently rely on a complicated series of mechanisms and clamps to heat the wire and then transmit the forces to the structure. In addition, the Boeing proof of concept model presented in this work employs two sets of monolithic actuators organised in an opposing or antagonistic configuration to provide active and controlled forces to expand and compress the nozzle diameter. The model proved that a nozzle area may be managed efficiently throughout a broad variety of nozzle flow conditions and nozzle areas. ${ }^{[8]}$

\section{NOZZLE DESIGN}

To place the actuator in its Martensite position, most SMA actuator systems use on passive return forces, such as springs or compliant materials. When heated, the return forces oppose the forces created by the SMA components. When heated, the SMA acts against the return forces as well as any external stresses.The return forces stretch the SMA to its Martensite state when it is cooled. In order for the actuator to reach the right Martensite and Austenite positions, the SMA components, return forces, and external loads must be carefully balanced.It can result in large return pressures, especially when external loads are uncertain and variable. As a result, bigger SMA actuators may be required to counteract the higher return forces. External loads can vary considerably in size and direction for a given actuator position in many aerospace applications, making accurate balancing of the SMA and return forces even more challenging. Furthermore, because passive forces oppose active SMA elements, systems with a return actuation rate that is dependent on the SMA's cooling rate, which is frequently considerably slower than the heating rate, are created. ${ }^{[8]}$

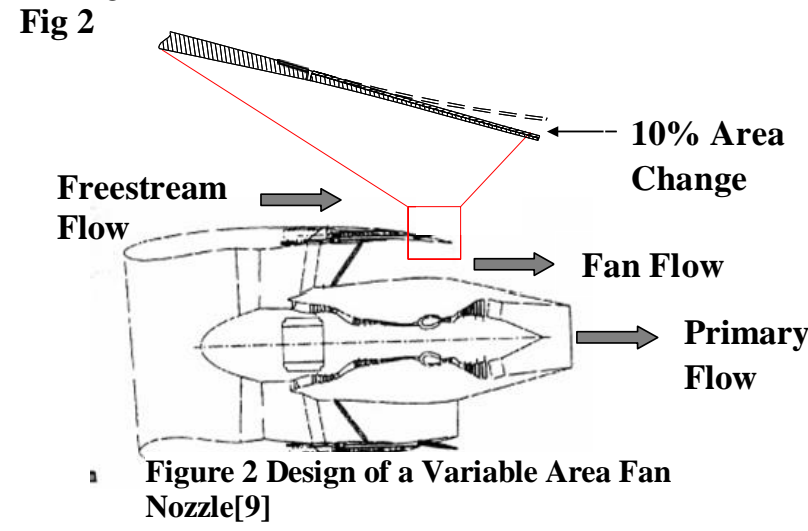


Active SMA members replace passive return forces in the antagonistic approach. Regardless of the size or direction of the external loads, variable amounts of force can be supplied in different directions to maintain the right amount of actuator displacement. The cooling rate of a single pair of actuators has no bearing on the orientation of the actuator. Before the other SMA elements are fully cooled, heating the opposite SMA elements might cause the actuator to reverse direction.

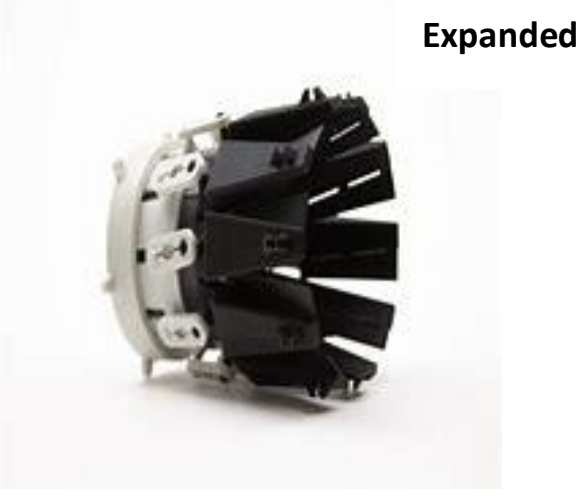

Figure 3 [A] Nozzle design with a variable area(3D printed nozzle). ${ }^{[23]}$

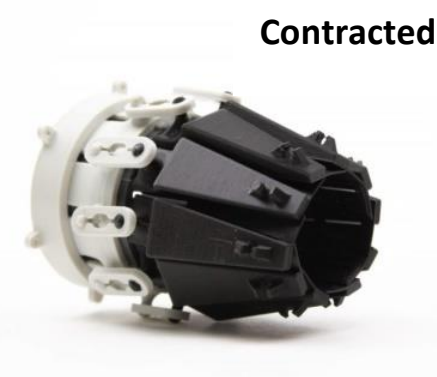

Figure $3[B]$ Nozzle design with a variable area(3D printed nozzle). ${ }^{[24]}$

The stresses on nozzle walls change based on mass flow, velocity, and nozzle form in the case of the Variable Area Nozzle. The nozzle had to keep a well-defined minimum area under all loads for this test, but it also had to be able to hold a programmed area up to $20 \%$ greater when flow conditions varied. To offer control power in both the expand and contract directions, the antagonistic design was used. Forces might be raised in either direction without relying on the cooling rate of the actuators.

\subsection{NOZZLE DESIGN}

Figure 3 depicts a portion of the nozzle. The output diameter of the fully open nozzle is $7 \mathrm{~cm}(2.75$ "). The final $2.86 \mathrm{~cm}$ (1.125") of the nozzle is made up of 12 overlapping
Aluminum panels. Half of the panels have SMA actuators that increase the nozzle diameter when heated, while the other half has SMA actuators that compress the nozzle diameter when heated. Around the nozzle, the expand and contract actuators alternate. The interlocks and actuator forces are set up such that the edges of each panel stay in touch with the edges of the panels next to it. Figure 4 shows a cross section diagram of an expanding section. A basic converging nozzle is connected to a support structure. Figure 3 shows how each of the interconnecting panels has a curved inner surface that matches the nozzle lines and a flat outer surface. A tiny rectangular piece of thin steel connects each of the panels to the support ring. The steel provides a hinge line that allows the panel to swivel away from the nozzle's centre while keeping it aligned with the nozzle. The steel shim supplies the panel with a minimal amount of restoring force. The steel was fitted with a strain gauge, and the tip displacement of each panel was linked to the bending strain of the steel attachment piece. Each panel was fitted with a SMA actuator composed of Ni-40Ti

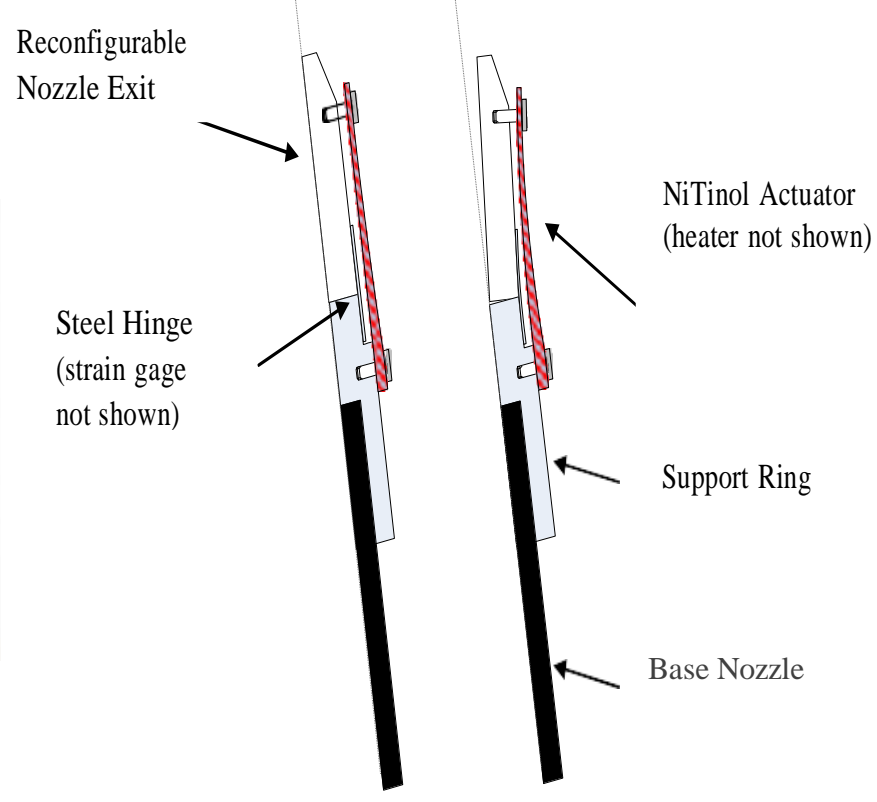

Figure 4 Design idea for a nozzle with a variable area ${ }^{[9]}$ 
(60 percent nickel by weight).

The actuator tip is mounted near the tip of each panel, and the actuator base is fastened to the support ring. Each actuator has a tiny resistive heater attached to its surface. When heated, the expanding actuators are programmed to curve away from the nozzle's centerline, dragging the panel tip along with them. When heated, the contracting actuators are programmed to bend towards the centerline, allowing the panel tip to join the nozzle flow.

The actuators were $1.9 \mathrm{~cm}$ wide $(0.75$ ") x $4.4 \mathrm{~cm}$ long $(1.75$ "), with a thickness of $2 \mathrm{~mm}(0.08$ ") at the base and $1 \mathrm{~mm}(0.04$ ") at the tip. Altering the distance between the panel and the actuator tip, either by changing the length of the tip screw for expanding actuators or by inserting shims between the actuator and the panel for contracting actuators, changes the amount of preload on the actuator. Figure 5 shows photos of the entire nozzle in both the fully extended and fully contracted

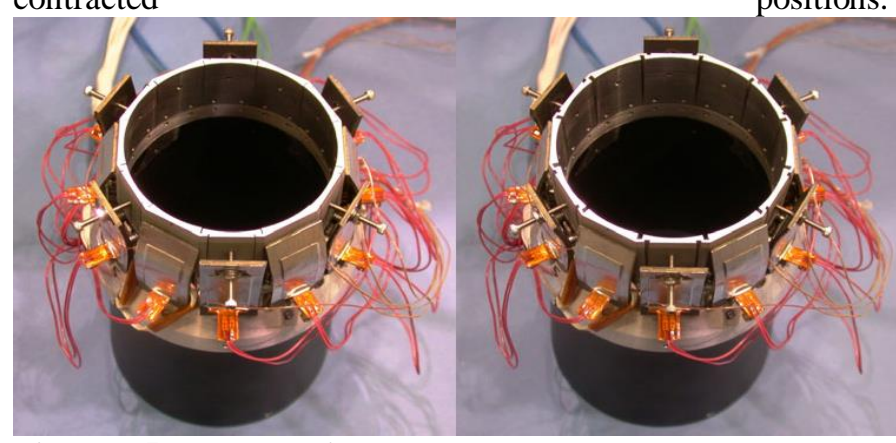

Figure 5 The variable area nozzle was completely constricted and $20 \%$ enlarged.[8]

\subsection{NICKEL RICH SMA ACTUATORS}

The SMA actuators are one of the keys to the variable area nozzle's success. The monolithic flexure actuator's simplicity is a significant benefit. It features a low part count and allows for easy connection to and adjustment of the nozzle's movable panels. The contracting and expanding actuators are the same size, but the Austenite form is different. The size of the actuators was not optimised for this test, and it is probable that they might be considerably decreased. The nickel-rich alloy $\mathrm{Ni}-40 \mathrm{Ti}$ is used to make the variable area nozzle actuators (60 percent $\mathrm{Ni}$ and 40 percent $\mathrm{Ti}$ by weight). It was only recently discovered that by heat treating $\mathrm{Ni}-40 \mathrm{Ti}$ properly, both superelastic and shape memory characteristics may be obtained from the same ingot. The transition temperatures may also be adjusted from $-55^{\circ} \mathrm{C}$ to $70^{\circ} \mathrm{C}$ with suitable heat treatment. Without cold work, recoverable strain of up to 2.5 percent was found, as well as a significant two-way effect and good cycle stability. The more stable nickel-rich material allows for thousands of actuator cycles without performance deterioration. ${ }^{[9]}$

Overview of Shape Memory Alloys
SMAs are a class of metallic alloys that, when subjected to a memorisation process between two transformation phases that is temperature or magnetic field dependent, can revert to their original form (shape or size). The shape memory effect is the name given to this transformation process (SME). The most basic application of these materials is that they can be easily deformed by applying an external force, and they will contract or recover to their original form when heated beyond a certain temperature, either externally or internally (Joule heating); or other relevant stimuli, such as a magnetic field for MSMAs. ${ }^{[10]}$ Memory Sculpture Due to their capacity to deform inelastically under mechanical strain and return to its original shape upon heating, alloys are exceptional actuator materials for adaptive constructions with significant shape control capabilities. The martensitic transition, a diffusionless process that occurs between two stable phases ${ }^{[16,17]}$, the low symmetry martensitic phase and the high symmetry austenitic phase, also known as the parent phase, is the reason underlying this unusual behaviour. ${ }^{[9]}$

\subsection{CONTROL AND INSTRUMENTATION}

The nozzle's departure region was controlled using a basic feedback control mechanism. The nozzle diameter was determined during testing by measuring the strain of six steel components that link the sliding nozzle panels to the support ring (see Fig. 4). The strain data were calibrated to the measured nozzle diameter prior to the nozzle test, and linear coefficients for strain vs. nozzle diameter were calculated. Only one set of actuators, either expanding or contracting, was actively heated at any one moment for these experiments, and a single heater voltage was supplied to the whole set. To avoid potential damage from both sets of Austenitic actuators, one set of actuators had to be close or below Mf at all times. Following testing, it was discovered that this is not essential, and that if both sets are actively managed, quicker cycle and better control with less overshoot are feasible. ${ }^{[9]}$

\section{DATA FOR TESTS}

Boeing's Quiet Air Facility in Seattle, Washington, was used to test the nozzle. The Mach number was changed up to 1.1 when fully enlarged. The control system was utilised to keep the diameter constant while altering the nozzle flow conditions and to change the diameter while maintaining constant flow conditions. At each condition, acoustic data was gathered using side line microphones, and flow field measurements were taken using PIV at various cross-sections.

\section{a. NOZZLE PERFORMANCE WITH VARIABLE AREA}

The nozzle was initially operated through a variety of sizes while maintaining a steady nozzle flow of 0.9 Mach. Figure 6 depicts the diameter of the nozzle and the controller set point 
vs. time. Both rising and decreasing diameters are shown to have reasonable control. An unknown disturbance in the test or control system resulted in a brief overheating of the contracting actuators, resulting in the significant overshoot shown at around 100 minutes. $^{[9]}$

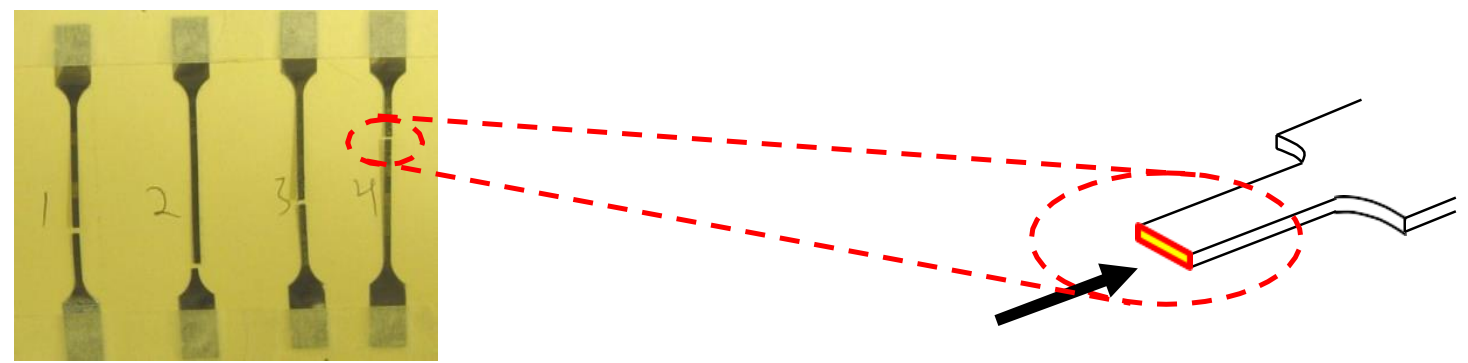

Figure 6 (a) Illustration of four distinct Ni57Ti43 specimens exhibiting random localisation of fatigue failure within the intended test gauge, (b) fractography schematic of the region of concern. ${ }^{[1]}$

\subsection{MICROSTRUCTURE AND FAILURE ANALYSIS}

The focus of this section is on the many factors that contributed to the failure of nickel-rich SMA actuators. The characterization effort was restricted to a study of the effects of various heat treatments and heat treatment conditions. Figure 6 shows four postmortem Ni57Ti43 specimens as an example of failure and validation of the required test gauge for locating fatigue failure. The failure happened at several random points inside the test gauge, indicating that the fatigue testing of the targeted gauge was legitimate. ${ }^{[11]}$

It was also tested with a fixed nozzle diameter and changing nozzle characteristics such as Mach and mass flow. As illustrated in Figure 8, the nozzle was tested at three diameters with Mach values ranging from 0 to 1.1. The Mach number on the graph is the notional steady state value for that time period, not actual recorded Mach data. Changes in the Mach number can obviously create substantial interruptions in the diameter control, but in most situations, recovery to the set point takes just a few minutes, which is sufficient for most VAFN applications. The magnitude and length of the interruptions might be greatly reduced if the controllers were optimised.

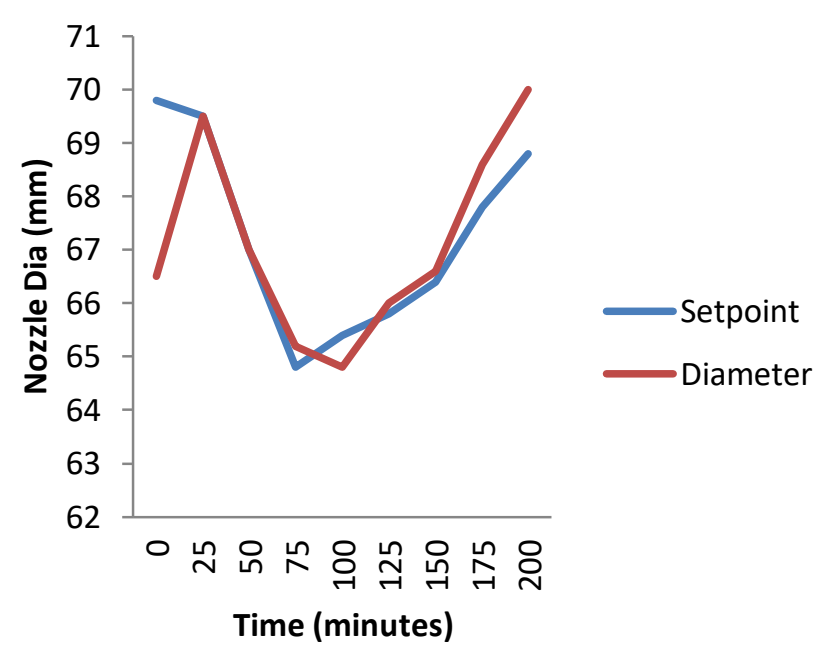

Figure. 7 At constant flow conditions, variable nozzle diameter.

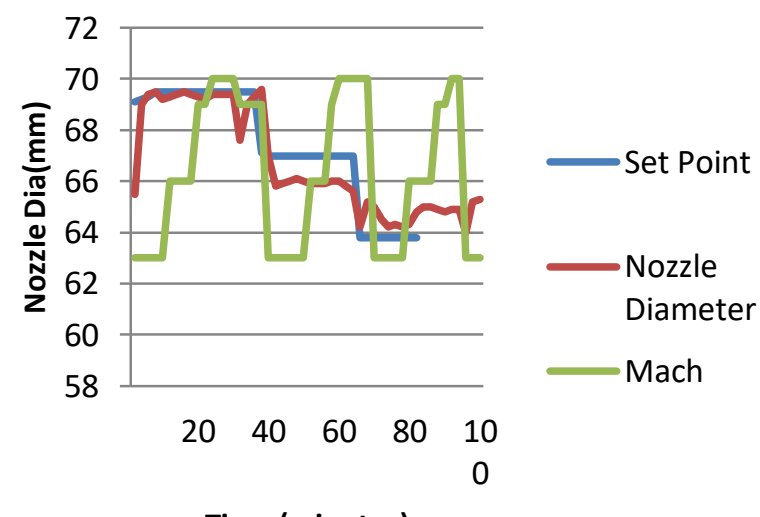

Time (minutes)

Figure. 8 Variable Mach number with constant diameters 


\subsection{MEASUREMENTS OF NOISE}

The noice measurements were taken with a linear microphone array set up on a line parallel to the jet axis at a distance of 33 $\mathrm{D}$, with microphones spaced every 5 degrees between 90 and 160 degrees. All of the data in this study are scaled to 286.7 $\mathrm{m} / \mathrm{s}$ (Mach 0.9 at $20^{\circ} \mathrm{C}$ ) and $100 \mathrm{D}$ for velocity and propagation radius. The strength of acoustic sources in the jet was measured using a nested spiral phased array with 157 microphones and a diameter of roughly $1 \mathrm{~m}$. The whole array was situated 1 metre from the jet axis, with the origin around 0.3 metre downstream of the nozzle exit. Figure 9 depicts the angular fluctuation of the overall sound pressure level (OASPL) derived from sideline microphone data spanning the aft quadrant. The subsonic mixing noise characteristic is shown in the directivity curve corresponding to the circular example depicted with the blue line, which gradually increases to a maximum at an angle of around $155^{\circ}$. Increased nozzle area reduces the required exit velocity for the same thrust. Because noise is directly connected to exit velocity with a power of roughly 8 on average and directly related to nozzle diameter with a power of 2 , increasing the nozzle diameter has a net advantage, as shown in the picture. The noise benefit is about $2 \mathrm{~dB}$ in all directions when the initial diameter is increased to $67 \mathrm{~mm}(2.65 \mathrm{in})^{[9]}$. The acoustic directivity varies at the greatest diameter of $70 \mathrm{~mm}$ (2.75 in), with an apparent gain at lower angles and a very minor advantage at the maximum radiation angle. This is most likely due to flow separation in the nozzle at the panel's hinge line, as well as an increase in turbulence levels in the shear layer produced by the slots that appear when the nozzle is at its largest exit area, as illustrated in Figure 5.

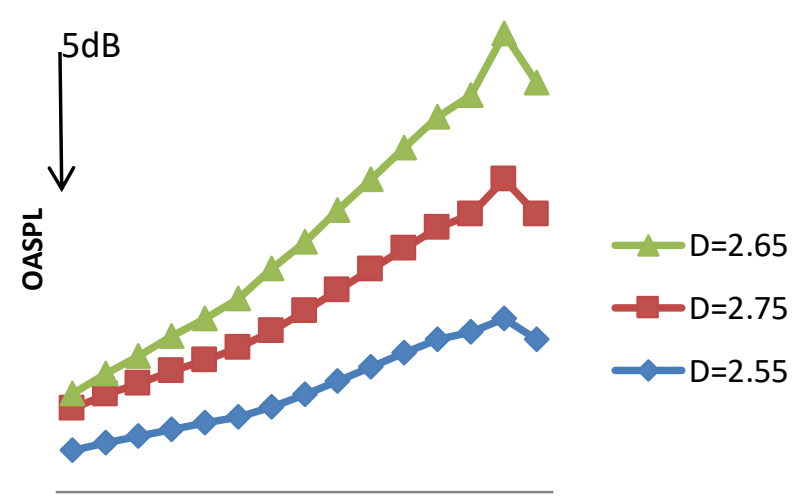

90100110120130140150160

ANGLE

Figure. 9 OASPL variation for three nozzle diameters.

For a source frequency of $2 \mathrm{kHz}$, equivalent to a Strouhal number of 0.5 , the noise source maps derived from the acoustic phased array are presented in Figure 10. As observed by the array, the colourful outlines show the minimum diameter, case SPL distribution emitted from the jet. To reduce side-lobe noise, the lowest SPL shown was set to be 8 $\mathrm{dB}$ lower than the maximum. The contour lines corresponding to a certain constant SPL value of $82 \mathrm{~dB}$ for the $2 \mathrm{kHz}$ frequency are used to compare the nozzle diameter instances. The solid contour line represents the nozzle flow with the smallest diameter, while the dashed and dotted lines represent two additional sizes. The source extent is first considerably decreased when the nozzle is expanded to $67 \mathrm{~mm}(2.65$ "), as seen by the big dotted line. However, increasing the aperture to $70 \mathrm{~mm}\left(2.75^{\prime \prime}\right)$ brings the source peak closer to the nozzle outlet and increases the extent. ${ }^{[9]}$ This is consistent with the findings from the sideline data. Such phenomenon might be caused by a change in flow character caused by probable partial separation.

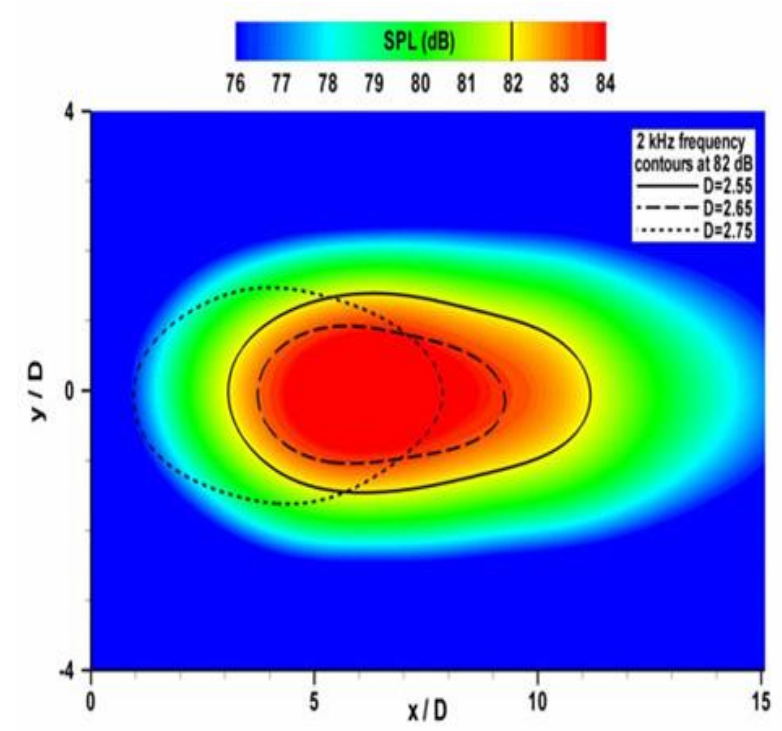

Figure 10 Three nozzle diamters noise source mps $^{[9]}$

The PIV measurements of the velocity fields were used to study the jet behaviour in the near field area for each nozzle configuration. At axial positions of $\mathrm{x} / \mathrm{D}=0.25,0.5$, and 1 , each jet was studied in three cross-sections near to the exit. At each cross-section, the time averaged velocity fields were derived from an ensemble of around 200 samples. The flow was recorded with nozzle diameters ranging from 2.55 to 2.75 inches in 0.1 increments. This study's PIV configuration was functionally comparable to that utilised by Alkislar et al.The findings are presented in Figure 11 at all axial positions, as well as at the nozzle openings with the smallest, middle, and largest diameters. The axial velocity is depicted in colourful contours in these images, while the exterior (low speed) border of the shear layer is depicted by a black solid line. Due to laser light reflections from the top of the nozzle at 12:00 sector, measurements are difficult at the closest cross-section 
of $x / D=0.25$. The flow is axisymmetric with a circular shear layer outer boundary when the nozzle is fully closed (Figure 11 (a-c)). When the nozzle is expanded to its median diameter, the flow appears to maintain its symmetry, with modest impacts on the shear layer seen as kinks at nozzle section junction points (Figure 10 (d-f)). However, as illustrated in Figure 11 (g-i), at the maximum nozzle diameter, the flow is greatly influenced at the shear layer's intersection areas. The longitudinal cavities that form between the nozzle sections produce local axial vorticity, which alters the shear layer's properties and causes the flow to diverge from axial symmetry. The rapid change in auditory properties suggests another alternative. It implies that rapid expansion of the nozzle area may have caused a partial or complete separation along the inner surface of the nozzle. ${ }^{[9]}$ demonstrate the use of active materials, such as SMAs, to improve lifting body performance ${ }^{[20]}$. The project was divided into two parts, the first of which required the greatest SMA. An SMA torque tube was utilised to begin spanwise wing twisting of a scaled-down F-18, while SMA wire tendons were used to activate hingeless ailerons. The SME is employed to provide actuation in each of these applications via shape recovery, which happens at a non-zero stress. In contrast to the preceding explanation, the stress state during actuation is changeable and is a result of the actuated structure's elastic response, in this case the wing. Although the SMA could offer satisfactory actuation at a scale of 16 percent, it was discovered that the SMA torque tube, in particular, was not strong enough to actuate a full-size wing. Fabrication of bigger SMA components for stronger actuation is now
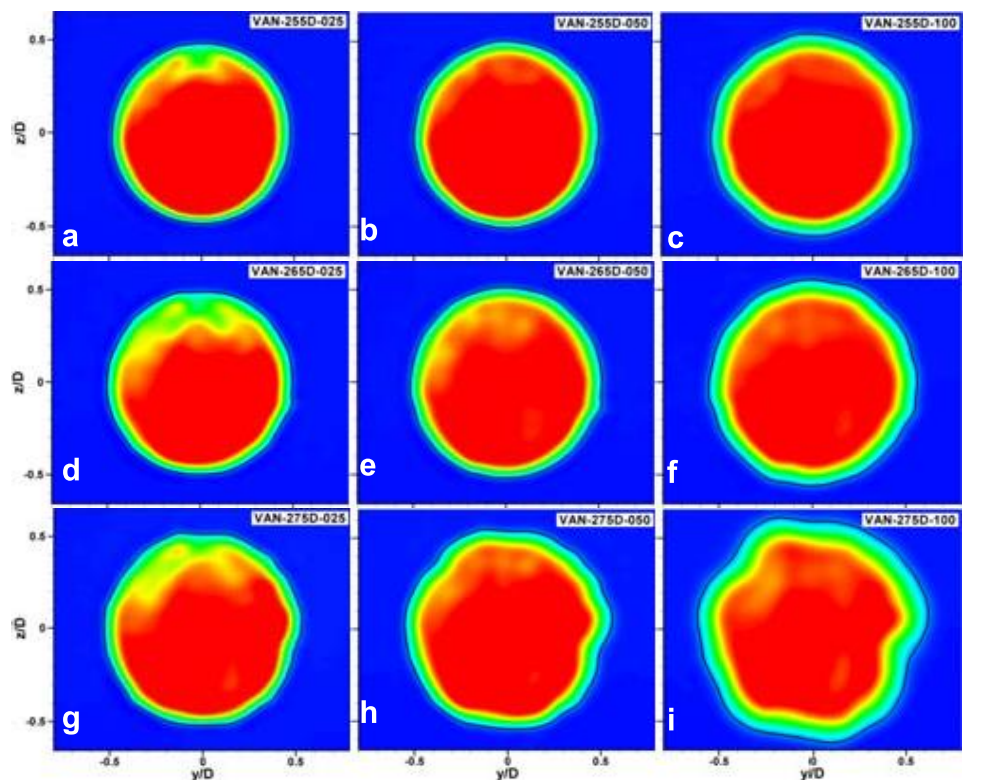

Figure. $11 \mathrm{D}=2.55^{\prime \prime}-2.75^{9}$ axial flow contours at $\mathrm{x} / \mathrm{D}=0.25$ to $1^{[9]}$

\section{EMERGING PROJECTS AND TECHNOLOGIES}

Boeing is currently developing and testing full-scale Variable Area Fan Nozzle designs that morph or reshape the carbon composite nozzle structure using an array of SMA monolithic actuators. As in this study, morphing improves the exit diameter while avoiding the discontinuities caused by rotating solid panels, thereby preserving connected flow. Seals will also be utilised to fill the space between panels, which appeared to enhance noise in the subscale test. ${ }^{[8]}$

The applications that are particular to fixedwing aircraft propulsion systems and structural designs will be explored first. The Smart Wing programme and the Smart Aircraft and Marine Propulsion System Demonstration (SAMPSON) ${ }^{[18,19]}$ are two of the most well-known fixed-wing initiatives in the past. The goal of the Smart Wing initiative was to develop and possible as SMA material vendors continue to expand their output. ${ }^{[14]}$

\section{CONCLUSION}

SMA actuators designed in an antagonistic design were used to create a subscale proof of concept of a changeable area jet nozzle. With altering nozzle flow parameters, a simple PID feedback controller maintained constant diameter and varied diameter control with constant flow circumstances. At Mach rates up to 1.1 , area control of $0 \%$ to $20 \%$ increased area was shown. When the space was expanded, acoustic data from side line microphones revealed a considerable reduction in nozzle noise. PIV flow field studies at many cross-sections revealed considerable effects from the interlocking panel joints. 


\section{REFERENCE}

[1] J.H. Mabe, R.T. Ruggeri, E. Rosenzweig, and C. Yu, "NiTinol Performance Characterization and Rotary Actuator Design", SPIE Smart Structures and Materials 2004, SPIE-5388-11, San Diego CA, March 2004.

[2] J. Mabe, R. Ruggeri, F. Calkins, "Characterization of Nickel-rich NiTinol Alloys for Actuator Development", The International Conference on Shape Memory and Superelastic Technologies, Pacific Grove,

CA, May 7-11, 2006

${ }^{[3]}$ F. Calkins, G. Butler, and J. Mabe, "Variable Geometry Chevrons for Jet Noise Reduction",AIAA- 2006-2546, $12^{\text {th }}$ AIAA/CEAS Aeroacoustics Conference, Cambridge MA, May 2006.

${ }^{[4]}$ J.H. Mabe, F.T. Calkins, G.W. Butler, "Boeing's Variable Geometry Chevron: Morphing aerostructure for jet noise reduction," 47nd AIAA Adaptive Structures Conference, AIAA-2006-2142, Newport RI, May 2006.

${ }^{[5]}$ F.T. Calkins, J.H. Mabe, and G.W. Butler, "Boeing's Variable Geometry Chevron: morphing aerospace structures for jet noise reduction.”, SPIE Smart Structures and Materials 2006, SPIE-6171-24, San Diego CA, March 2006.

[6] R. Cabell, N. Schiller, J. H. Mabe, R.T. Ruggeri, and G.W. Butler, "Feedback Control of a Morphing Chevron for Takeoff and Cruise Noise Reduction", Active 2004, Williamsburg VA, September 2004.

[7] R Woodward, C. Hughes, G. Podboy, "Aeroacoustic analysis of fan noise reduction with increasing bypass nozzle area," AIAA 2005-3075, AIAA Aeroacoustic, Monterey CA, 2005.

[8] Alkislar, M. B., Krothapalli, A., and Butler, G. W., "The Effect of Streamwise Vortices on the Aeroacoustics of a Mach 0.9 Jet," J. Fluid Mech., Vol. 578, March 2007, pp. 139-169.

${ }^{[9]}$ MABE, JAMES, 2008, Variable area jet nozzle for noise reduction using shape memory alloy actuators. The Journal of the Acoustical Society of America. 2008. Vol. 123, no. 5, p. 3871-3871. DOI 10.1121/1.2935758. Acoustical Society of America (ASA)

[10] Theodoros Machairas, Alexandros Solomou, Dimitris Saravanos, "A Morphing Chevron Actuated By Shape Memory Alloy Wires For Noise Reduction",researchgate,2014

${ }^{[11]}$ MOHD JANI, JARONIE, LEARY, MARTIN, SUBIC, ALEKSANDAR and GIBSON, MARK A., 2014, A review of shape memory alloy research, applications and opportunities. Materials \& Design (1980-2015). 2014. Vol. 56, p. 1078-1113. DOI 10.1016/j.matdes.2013.11.084. Elsevier BV
[12] Gangbing Song and Ning Ma, Nicholas Penney, Todd Barr, Ho-Jun Lee and Steven M. Arnold, "Design and Control of a Proof-of-Concept Active Jet Engine Intake Using Shape Memory Alloy Actuators", 2011 ntrs.nasa.gov

https://ntrs.nasa.gov/api/citations/20040082466/downloads/20 040082466.pdf

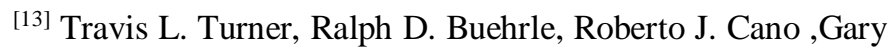
A. Fleming, "Design, fabrication, and testing of SMA enabled adaptive chevrons for jet noise reduction", 2004 - spiedigitallibrary.org

https://www.spiedigitallibrary.org/conference-proceedings-ofspie/5390/0000/Design-fabrication-and-testing-of-SMAenabled-adaptive-chevrons-for/10.1117/12.540013.short

[14] ] D J Hartl , D C Lagoudas, "Aerospace applications of shape memory alloys", 2007 - journals.sagepub.com

https://journals.sagepub.com/doi/abs/10.1243/09544100jaero2 $\underline{11}$

[15] F.T. Calkins and G.W. Butler, "Subsonic Jet Noise Reduction Variable Geometry Chevron", 42nd AIAA Aerospace Sciences Meeting and Exhibit, AIAA-20040190, Reno NV, January 2004.

${ }^{[16]}$ Lagoudas, D.C., Shape Memory Alloys Modeling and Engineering Applications, Springer, New York, 2008.

[17] Otsuka, K., Wayman, C.M., Shape Memory Materials, Cambridge University Press, 1998.

${ }^{[18]}$ Garcia, E. Smart structures and actuators: past, present, and future. In Proceedings of SPIE, Smart Structures and Materials, San Diego, CA, 17-21 March 2002, pp. 1-12.

${ }^{[19]}$ Sanders, B., Crowe, R., and Garcia, E. Defense advanced research projects agency - smart materials and structures demonstration program overview. J. Intell. Mater. Syst. Struct., 2004, 15, 227-233.

${ }^{[20]}$ Kudva, J. Overview of the DARPA smart wing project. J. Intell. Mater. Syst. Struct., 2004, 15, 261-267.

[21]

www.researchgate.net $\% 2$ fprofile\%2fQinghua Guan $2 \% 2 \mathrm{f}$ publication \%2f $295877562 \% 2$ ffigure $\% 2$ ffig $14 \% 2 \mathrm{fAS} \% 3 \mathrm{a}$ $660984708485121 \% 401534602443586 \% 2$ fFull-scaleflight-tests-of-SMA-actuated-variable-geometrychevrons-on-a-Boeing-777300ER.png\&exph $=373 \&$ expw $=850 \& q=$ boing + variable $+g$ eomertry+chevron\&simid $=608020975278959099 \&$ FOR M=IRPRST\&ck=BDFDC9EE7D6A183CE878475E2898 AEBD\&selectedIndex $=2$

[22]

https://www.bing.com/images/search?view=detailV2\&cci $\mathrm{d}=\mathrm{sBO5SF} 2 \mathrm{~S} \& \mathrm{id}=86 \mathrm{D} 4 \mathrm{E} 1 \mathrm{~A} 2615331 \mathrm{BC} 204 \mathrm{DE} 031 \mathrm{~F} 809$ 5794C80BD262\&thid=OIP.sBO5SF2SD7T-

AQ2RWDUqbwHaEF\&mediaurl=https $\% 3 \mathrm{a} \% 2 \mathrm{f} \% 2 \mathrm{ff} . \mathrm{ptcd}$ n.info $\% 2$ f $180 \% 2 \mathrm{f} 037 \% 2 \mathrm{f} 000 \% 2 \mathrm{fnxg} 8 \mathrm{aify} 45 \mathrm{fw} \ln 0 \mathrm{Irn}-$ o.jpg\&exph $=377 \&$ expw= $684 \& q=$ boing + variable + geomer 
International Journal of Engineering Applied Sciences and Technology, 2021

Vol. 6, Issue 3, ISSN No. 2455-2143, Pages 275-283

Published Online July 2021 in IJEAST (http://www.ijeast.com)

try+chevron\&simid $=608012643042202552 \&$ FORM $=$ IRP RST\&ck=7B84898CCA0B55298EEB9FEF17CDB10F\&

selectedIndex $=62$

[23]

https://cdn2.colorfabb.com/wpcontent/uploads/2018/09/img_75381024x1024.jpg?x83402

[24]

https://cdn2.colorfabb.com/wpcontent/uploads/2018/09/img_7534-1024x683.jpg 